\title{
Carnitine levels and cardiac functions in children with solid malignancies receiving doxorubicin therapy
}

\author{
Anant Khositseth, \\ Suwadee Jirasakpisarn, \\ Samart Pakakasama, \\ Lulin Choubtuym ${ }^{l}$, \\ Duangrurdee \\ Wattanasirichaigoon \\ Department of Pediatrics, \\ ${ }^{1}$ Research Center, Faculty of \\ Medicine, Ramathibodi Hospital, \\ Mahidol University, \\ Bangkok, Thailand
}

\begin{abstract}
A B S T R A C T
Aim: Previous studies demonstrated l-carnitine decreasing doxorubicin-induced cardiotoxicity. Our objectives were to study carnitine levels and cardiac functions in children treated with doxorubicin and the effect of short-term l-carnitine supplements. Materials and Methods: Serial carnitine levels and cardiac functions were obtained in children with newly diagnosed solid malignancies before doxorubicin, after cumulative doses of $\geq 150 \mathrm{mg} / \mathrm{m}^{2}$ and $\geq 300 \mathrm{mg} / \mathrm{m}^{2}$, respectively. Oral l-carnitine $100 \mathrm{mg} / \mathrm{kg} /$ day for 3 days were given to the children treated with doxorubicin at cumulative doses of $\geq 150 \mathrm{mg} / \mathrm{m}^{2}$ and $\geq 300 \mathrm{mg} / \mathrm{m}^{2}$. Carnitine levels and cardiac functions were also obtained in those children before and after short-term oral I-carnitine at each cumulative dose of doxorubicin. Results: Five children ( 3 females), median age of 9.1 years (range 1.5-13 years) with newly diagnosed solid malignancies were enrolled in the study. Free carnitine (FC) tended to decrease while acyl-carnitine $(A C)$ increased making $A C / F C$ ratio increased after cumulative dose of $\geq 150$ and $\geq 300 \mathrm{mg} / \mathrm{m}^{2}$ but the statistics was not significant. Left ventricular (LV) systolic function was not significantly changed. Interestingly, LV global function (LV myocardial performance index) was significantly increased after $150 \mathrm{mg} / \mathrm{m}^{2}$ (median $0.39,0.27-0.51$ ) and $300 \mathrm{mg} / \mathrm{m}^{2}$ (median 0.46, 0.27-0.50) when compared to baseline (median 0.28, 0.14-0.48) $(P=0.05)$. Carnitine levels and cardiac functions were not significantly changed after oral I-carnitine supplement at cumulative dose of $\geq 150 \mathrm{mg} / \mathrm{m}^{2}(n=6)$ and $\geq 300 \mathrm{mg} /$ $\mathrm{m}^{2}(n=9)$. Conclusions: Carnitine levels tended to decrease after doxorubicin treatment. LV global dysfunction was documented early after doxorubicin. However, short-term l-carnitine supplement did not improve cardiac function.
\end{abstract}

Key words: Anthracycline, cardiac function, cardiac toxicity, children

\author{
Address for correspondence: \\ Dr. Anant Khositseth, \\ Department of Pediatrics, Faculty \\ of Medicine, Ramathibodi Hospital \\ Mahidol University, 270 Rama VI, \\ Ratchathevee, Bangkok 10400, \\ Thailand. \\ E-mail: alaks@diamond.mahidol. \\ ac.th
}




\section{MATERIALS AND METHODS}

Part one of the study was a prospectively longitudinal cohort study of children aged less than 15 years with newly diagnosed solid malignancies including rhabdomyosarcoma, Ewing's sarcoma, osteosarcoma, fibrosarcoma, and hemangiopericytoma who were planning to receive doxorubicin for their chemotherapy regimens at single center of the University Hospital between March 2008 and April 2009. Carnitine levels and echocardiography were performed in these children before doxorubicin treatment, after cumulative dose of doxorubicin $\geq 150$ and $300 \mathrm{mg} / \mathrm{m}^{2}$, respectively.

Part two of the study was a cross-sectional study of children aged less than 15 years with solid malignancies as described above who received doxorubicin $\geq 150$ and 300 $\mathrm{mg} / \mathrm{m}^{2}$. These children received l-carnitine orally at 100 $\mathrm{mg} / \mathrm{kg} /$ day for three consecutive days. Carnitine levels and echocardiography were performed in these children before and after l-carnitine supplementation.

Exclusion criteria were primary/secondary carnitine deficiency and inborn error of metabolism, cardiovascular diseases, liver diseases, renal diseases, malabsorption or chronic diarrhea, immunocompromised patients, and valproic acid therapy. The study was conducted following an approval by Institutional Review Board and written informed consents given by parents of the patients.

\section{Plasma carnitine measurement}

Five milliliter of heparinized blood was collected from each patient at the times described above in those two parts of the study. Plasma specimens obtained by centrifugation at 3000 $g$ for $10 \mathrm{~min}$ at room temperature were kept frozen at $-80^{\circ} \mathrm{C}$ until analysis. Plasma total carnitine (TC) and free carnitine (FC) levels were determined by using spectrophotometric method previously described by Alhomida et al. ${ }^{[10]}$ with some modifications. ${ }^{[1,12]}$ Acylcarnitine (AC) level was calculated as the difference between TC and FC levels. All carnitine levels were expressed as median and rage. The criteria for diagnosis of carnitine deficiency are $\mathrm{FC}<20 \mu \mathrm{mol} / \mathrm{L}$ (absolute deficit) or $\mathrm{AC} / \mathrm{FC}$ ratio $>0.4$ (relative deficit).

\section{Echocardiography}

A 2D, M-mode, color, Doppler echocardiography was performed in all patients at the times described above by single pediatric cardiologist (A.K.) blinded to the clinical data. Systolic function was shown as left ventricular (LV) ejection fraction (EF) and fractional shortening (FS) calculated by $\mathrm{M}$-mode of the left ventricle in systole and diastole. Myocardial performance index (MPI) of the left ventricle was calculated by Doppler of the mitral valve inflow and the LV outflow as described. ${ }^{[13]}$ The normal values for LVEF and LVFS are $\geq 55 \%$ and $\geq 25 \%$, respectively.

The normal range for LV MPI is $0.33 \pm 0.05 .^{[14]}$ In this study, the authors used LV MPI $\geq 0.40$ as an cut-off for LV global dysfunction.

\section{Statistical analysis}

All continuous data were expressed as median and range and were compared using Mann-Whitney $U$ test in two independent samples and Kruskal-Wallis test for several independent samples. All data were analyzed by a statistical analysis system (SPSS: Statistical Package for the Social Science version 16.0$)$. $P$ value $\leq 0.05$ was considered statistically significant.

\section{RESULTS}

\section{Part I of the study}

Five children ( 3 females), median age of 9.1 years (range 1.5-13 years) with newly diagnosed solid malignancies were enrolled in the study. Their demographic data were shown in Table 1.

Serum TC, FC, AC, and AC/FC ratio were not significantly changed before and after doxorubicin $\geq 150$ and $\geq 300 \mathrm{mg} /$ $\mathrm{m}^{2}$. However, there was a trend that FC decreased while $\mathrm{AC}$ increased making $\mathrm{AC} / \mathrm{FC}$ ratio to be increased while TC was unchanged [Table 2].

LV systolic function represented by LVEF and LVFS was not significantly changed before and after doxorubicin at cumulative dose of $\geq 150$ and $\geq 300 \mathrm{mg} / \mathrm{m}^{2}$. One patient had LV systolic dysfunction (EF 54\% and FS 21\%)

\begin{tabular}{|c|c|c|c|c|c|c|}
\hline Patient & Sex & Age (years) & BW (kg) & BW (percentile) & Tumor & $\mathrm{DOX} \mathrm{mg} / \mathrm{m}^{2}$ \\
\hline 1 & $\mathrm{~F}$ & 9.1 & 26 & $P_{10-25}$ & $\mathrm{E}$ & 375 \\
\hline 2 & M & 10 & 20 & $<P_{3}$ & $\mathrm{O}$ & 300 \\
\hline 3 & $\mathrm{~F}$ & 1.5 & 13 & $P_{75}$ & $\mathrm{H}$ & 300 \\
\hline 4 & $\mathrm{~F}$ & 9 & 23 & $P_{25}$ & $\mathrm{O}$ & 300 \\
\hline 5 & M & 13 & 39 & $P 25-50$ & $\mathrm{O}$ & 300 \\
\hline
\end{tabular}

BW - Body weight; DOX - Doxorubicin; E - Ewing's sarcoma; F - Female; H - Hemagiopericytoma; M - Male; O - Osteosarcoma 
after doxorubicin at cumulative dose of $\geq 300 \mathrm{mg} / \mathrm{m}^{2}$. Interestingly, this patient was discontinued doxorubicin but his LVEF was still worsening; he died due to severe sepsis, septic shock, and severe LV dysfunction 3 months later.

LV global function represented by LV MPI was significantly increased after doxorubicin at cumulative dose of $\geq 150$ (median 0.39 , range $0.27-0.51$ ) and $\geq 300$ $\mathrm{mg} / \mathrm{m}^{2}$ (median 0.46 , range $0.27-0.50$ ) when compared to before doxorubicin (median 0.28, range 0.14-0.48), $P=0.05$. Moreover, $2 / 5$ and $3 / 5$ patients at cumulative dose of $\geq 150$ and $\geq 300 \mathrm{mg} / \mathrm{m}^{2}$, respectively, had LV MPI $\geq 0.40$, which indicated LV global dysfunction. However, LV MPI after doxorubicin at cumulative dose of $\geq 150$ $\mathrm{mg} / \mathrm{m}^{2}$ was not significant different when compared to LV MPI after doxorubicin at cumulative dose of $\geq 300$ $\mathrm{mg} / \mathrm{m}^{2}$ [Figure 1].

\section{Part II of the study}

Six children (3 females), median age of 9.6 years (range 1.5-14 years) having cumulative dose of doxorubicin $\geq 150 \mathrm{mg} / \mathrm{m}^{2}$ and 9 children (5 females), median age of 9.0 years (range 1.5-13 years) having cumulative dose of doxorubicin $\geq 300 \mathrm{mg} / \mathrm{m}^{2}$ were enrolled in the study. After oral l-carnitine at $100 / \mathrm{kg} /$ day for three consecutive days in children having cumulative dose of doxorubicin $\geq 150$ $\mathrm{mg} / \mathrm{m}^{2}$, median TC, FC, AC, and AC/FC levels were not significantly increased [Table 3], whereas median LVEF, 60.5\% (52-65\%); LVFS 32.5\% (30-34\%); and LV MPI $0.49(0.27-0.56)$ were also not significantly changed when compared to those after l-carnitine supplement for 3 days;
LVEF 64.5\% (50-72\%); LVFS 34\% (32-42\%), and LV MPI 0.53 (0.32-0.66), respectively.

After oral l-carnitine at $100 / \mathrm{kg} /$ day for three consecutive days in children having cumulative dose of doxorubicin $\geq 300 \mathrm{mg} / \mathrm{m}^{2}$, TC and FC were significantly increased $(P=0.005)$ [Table 3]; however, median LVEF 61\% (54-68\%); LVFS 33\% (28-38\%); and LV MPI 0.46 (0.18-0.63) were not significantly changed when compared to those after 1-carnitine supplement for three consecutive days; LVEF 64\% (44-74\%); LVFS 35\% (21-43\%); and LV MPI 0.37 (0.28-0.55), respectively.

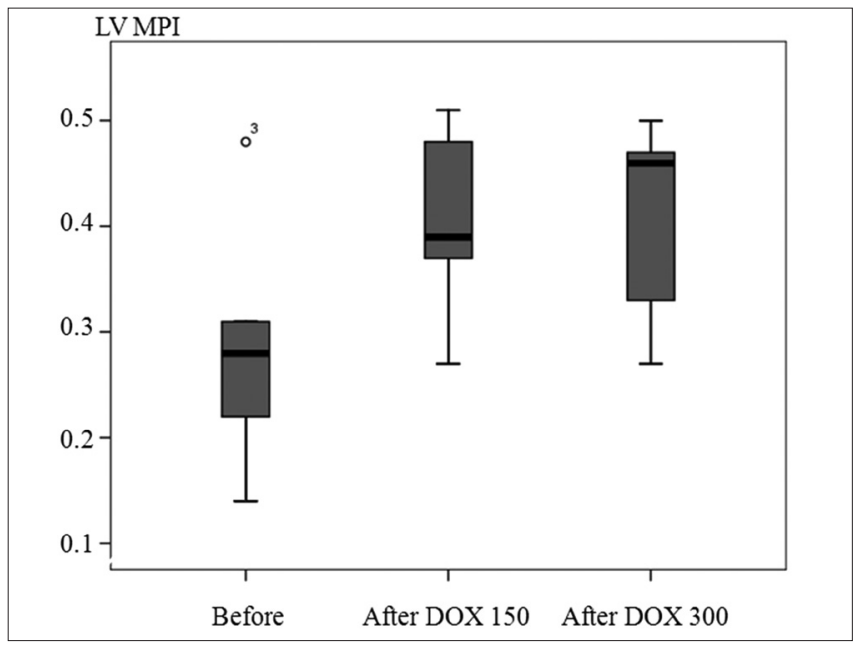

Figure 1: Boxplot of left ventricular myocardial performance index (MPI) before doxorubicin (DOX) treatment, after doxorubicin treatment at cumulative dose $>150$ and $>300 \mathrm{mg} / \mathrm{m}^{2}$

\begin{tabular}{|c|c|c|c|c|}
\hline \multirow[t]{2}{*}{ Groups } & \multicolumn{3}{|c|}{ Plasma carnitine level ( $\mu \mathrm{mol} / \mathrm{L})$} & \multirow[t]{2}{*}{$\mathrm{AC} / \mathrm{FC}$} \\
\hline & TC & FC & AC & \\
\hline \multirow[t]{2}{*}{ Before DOX } & 60.2 & 54.6 & 3.8 & 0.07 \\
\hline & $48.4-64.7$ & $47 \cdot 3-62.3$ & $1-10.1$ & $0.02-0.18$ \\
\hline \multirow[t]{2}{*}{ After DOX $\geq 150 \mathrm{mg} / \mathrm{m}^{2}$} & 59.2 & 48 & 6.3 & 0.13 \\
\hline & $37.1-78.3$ & $36.4-57.1$ & $0.69-28.2$ & $0.01-0.56$ \\
\hline \multirow[t]{2}{*}{ After DOX $\geq 300 \mathrm{mg} / \mathrm{m}^{2}$} & 56.6 & 43.6 & 8.4 & 0.29 \\
\hline & $53.6-73.6$ & $39.5-68.5$ & $2.3-16.9$ & $0.04-0.36$ \\
\hline
\end{tabular}

AC - Acylcarnitine; AC/FC - Acylcarnitine to free carnitine ratio; DOX - Doxorubicin; FC - Free carnitine; TC - Total carnitine

\begin{tabular}{|c|c|c|c|c|c|c|c|c|}
\hline \multirow[t]{3}{*}{ Groups } & \multicolumn{8}{|c|}{ Plasma carnitine level ( $\mu \mathrm{mol} / \mathrm{L})$} \\
\hline & \multicolumn{2}{|c|}{ TC } & \multicolumn{2}{|c|}{ FC } & \multicolumn{2}{|c|}{$\mathrm{AC}$} & \multicolumn{2}{|c|}{$\mathrm{AC} / \mathrm{FC}$} \\
\hline & Baseline & $\begin{array}{l}\text { After oral } \\
\text { carnitine }\end{array}$ & Baseline & $\begin{array}{l}\text { After oral } \\
\text { carnitine }\end{array}$ & Baseline & $\begin{array}{l}\text { After oral } \\
\text { carnitine }\end{array}$ & Baseline & $\begin{array}{l}\text { After oral } \\
\text { carnitine }\end{array}$ \\
\hline After DOX & 60.2 & 72.1 & 49.1 & $59 \cdot 5$ & 8.7 & 12.7 & 0.17 & 0.27 \\
\hline$\geq 150 \mathrm{mg} / \mathrm{m}^{2}$ & $37.1-38.3$ & $35 \cdot 5^{-128.8}$ & $36.4-58.8$ & $27.8-88.5$ & $0.7-28.2$ & $4.9-40.2$ & $0.01-0.56$ & $0.09-0.45$ \\
\hline After DOX & 55.7 & 87.7 & 43.6 & 73.0 & 8.8 & 16.4 & 0.23 & 0.32 \\
\hline$\geq 300 \mathrm{mg} / \mathrm{m}^{2}$ & $46.3-73.6$ & $37.1-126.2$ & $37.5-68.5$ & $24.0-94.6$ & $2.3-18.1$ & $3.0-41.0$ & $0.04-0.43$ & $0.04-0.54$ \\
\hline
\end{tabular}

AC - Acylcarnitine; AC/FC - Acylcarnitine to free carnitine ratio; DOX - Doxorubicin; FC - Free carnitine; TC - Total carnitine 


\section{DISCUSSIONS}

Doxorubicin can lead to cardiotoxicity which can be acute occurring during and within few days after administration including chest pain due to pericarditis, palpitation due to arrhythmias, and acute left ventricle failure due to myocarditis. ${ }^{[15]}$ All these are reversible with appropriate treatments. The incidence of acute cardiotoxicity is approximately $11 \% \cdot{ }^{[15]}$ The incidence of chronic doxorubicin cardiotoxicity is approximately $1.7 \%$, which leads to doxorubicin cardiomyopathy primarily related to the accumulative dose of doxorubicin. ${ }^{[16]}$ The present study demonstrated that systolic function assessed by LVEF and LVFS was not significantly changed after the cumulative dose $\geq 150$ and $\geq 300 \mathrm{mg} / \mathrm{m}^{2}$. Interestingly, one case developed LV systolic dysfunction (LV EF=54\%) at cumulative dose $\geq 300 \mathrm{mg} / \mathrm{m}^{2}$. As a guideline for discontinuing doxorubicin, the suggested values of LVEF and LVFS are below $55 \%$ and $29 \%$, respectively. ${ }^{[17]}$ Although doxorubicin was discontinued in this patient, he died 3 months later due to severe sepsis and more progressive on his LV dysfunction.

In contrast, LV MPI which represented LV global function (combined systolic and diastolic myocardial function) ${ }^{[13]}$ was significantly increased after doxorubicin treatment even after the cumulative dose $\geq 150 \mathrm{mg} / \mathrm{m}^{2}$. Moreover, $2 / 5$ and $3 / 5$ patients at cumulative dose $\geq 150$ and $\geq 300 \mathrm{mg} /$ $\mathrm{m}^{2}$, respectively, had LV MPI $\geq 0.40$ which indicated LV global dysfunction. This may indicate that even at the low cumulative dose of doxorubicin, the LV global dysfunction had already settled. Senju et al. ${ }^{[18]}$ reported in 23 adult patients treated with doxorubicin and demonstrated that a change in the Tei-index or LV MPI was more sensitive indicator of early cardiotoxicity induced by doxorubicin than LVEF. Our findings may indicate early myocardial damage induced by lower cumulative dose of doxorubicin than that required to cause obvious cardiotoxicity represented by a significant decrease in LVEF or LVFS. The authors considered that LV MPI may be a good indicator of doxorubicin-induced cardiotoxicity and should be included in routine echocardiography for follow up in these patients.

Yaris et al., ${ }^{[19,20]}$ reported that there was a trend toward decreasing serum carnitine levels with increasing the cumulative doses of doxorubicin and found no significant relationship between carnitine levels and nutritional status of patients either at diagnosis or during treatment. From these results, it is implied that inadequate intake of carnitine or its precursors could not be solely responsible for decrease in carnitine levels. In contrast, Yoon et al., ${ }^{[21]}$ studied in rats and reported that doxorubicin caused significant elevations of plasma FC, AC, and TC levels with relatively higher increase in $\mathrm{AC}$ than $\mathrm{FC}$, resulting in increased AC/FC ratio. Recent study in rat demonstrated that doxorubicin therapy resulted in dose-dependent decrease in FC and increase in AC causing increased $\mathrm{AC} / \mathrm{FC}$ ratio in both serum and rat heart tissues, leading to the conclusion that myocardial carnitine level may be a mechanism of development of doxorubicin cardiotoxicity ${ }^{[7]}$ Carnitine level in patients with solid tumor after doxorubicin treatment in the present study had a trend of decreased $\mathrm{FC}$, increased $\mathrm{AC}$, and increased $\mathrm{AC} / \mathrm{FC}$ ratio as previously reported in animal models [Table 2], although the statistics was not significantly different, probably due to the small number of the patients. According to the criteria for diagnosis of absolute carnitine deficiency (FC $<20 \mu \mathrm{mol} / \mathrm{L}$ ) or for relative carnitine deficiency (AC/ FC ratio $>0.4$ ), only one patient met the criteria for the diagnosis of relative carnitine deficiency. At the cumulative dose of doxorubicin $\geq 150 \mathrm{mg} / \mathrm{m}^{2}$, this patient had normal FC $(50.1 \mu \mathrm{mol} / \mathrm{L})$ but had high AC/FC (0.56). This patient had normal LV systolic function but impaired LV global dysfunction (LIMP=0.56). Interestingly, at the cumulative dose of doxorubicin $\geq 300 \mathrm{mg} / \mathrm{m}^{2}$, this patient $\mathrm{did}$ not have carnitine deficiency (FC $57.8 \mu \mathrm{mol} / \mathrm{L}$ and AC/FC 0.04 ) and his LV global dysfunction returned to normal $(\mathrm{LIMP}=0.33)$.

Various drugs have been tried to prevent doxorubicininduced cardiotoxicity including 1-carnitine. ${ }^{[22]}$ In the present study, the authors evaluated the short-term effect of l-carnitine by supplying $100 \mathrm{mg} / \mathrm{kg} /$ day of oral l-carnitine for 3 days and found that no significant changes of serum carnitine levels and cardiac functions. Cardiac function, either systolic function, assessed by LVEF, LVFS, or global function, assessed by LV MPI, were not significantly changed after short-term supplement of 1-carnitine. This may be explained by two reasons: first, there was no carnitine deficiency before treatment and second, the sample size was small. Given the essential role of 1-carnitine in transporting long fatty acids from the cytoplasmic compartment into mitochondria for beta-oxidation to produce energy, ${ }^{[23]}$ inhibition of this vital pathway in the heart as a result of carnitine deficiency has been shown to impair myocardial function. ${ }^{[24]}$ Moreover, decreased myocardial level of FC is thought to be part of the mechanism involved in the progression of doxorubicininduced heart failure and cardiomyopathy. ${ }^{[24]}$ The present study demonstrated that there was a trend toward decreasing plasma carnitine levels after increasing cumulative doses of doxorubicin. So, the authors recommended to check carnitine level in children treated with doxorubicin especially when the cardiac function is impaired. In those selected cases, a supplement of l-carnitine may be helpful in the improvement of cardiac function. 


\section{CONCLUSIONS}

LV systolic function was not found at lower cumulative doses of doxorubicin, but LV global dysfunction was documented earlier after doxorubicin therapy. This should indicate the awareness and proper management in these patients when LV global dysfunction developed. Although carnitine level tended to decrease after doxorubicin treatment, short-term l-carnitine supplement for 3 days did not improve cardiac function. A longer period of carnitine supplement or other modalities of treatment needed to be further investigated.

\section{ACKNOWLEDGEMENT}

This work was supported by grants (2552-4) from Mahidol University to DW. DW is recipient of the Research Career Development Award, Faculty of Medicine, Ramathibodi Hospital, Mahidol University.

\section{REFERENCES}

1. Carter SK. Adriamycin: A review. J Natl Cancer Inst 1975;55:1265-74.

2. Kantrowitz NE, Bristow MR. Cardiotoxicity of antitumor agents. Prog Cardiovasc Dis 1984;27:195-200.

3. al-Shabanah O, Mansour M, el-Kashef H, al-Bekairi A. Captopril ameliorates myocardial and hematological toxicities induced by adriamycin. Biochem Mol Biol Int 1998;45:419-27.

4. Huang $X M$, Zhu $W H$, Kang ML. Study on the effect of doxorubicin on expressions of genes encoding myocardial sarcoplasmic reticulum $\mathrm{Ca} 2+$ transport proteins and the effect of taurine on myocardial protection in rabbits. J Zhejiang Univ Sci 2003;4:114-20.

5. Myers C. The role of iron in doxorubicin-induced cardiomyopathy. Semin Oncol 1998;25:10-4.

6. Sayed-Ahmed MM, Shaarawy S, Shouman SA, Osman AM. Reversal of doxorubicin-induced cardiac metabolic damage by L-carnitine. Pharmacol Res 1999;39:289-95.

7. Sayed-Ahmed MM. Increased serum and cardiac acyl-carnitine/ free carnitine ratio during development of doxorubicininduced cardiotoxicity. Saudi Pharm J 2007;15:120-6.

8. Bryant J, Picot J, Levitt G, Sullivan I, Baxter L, Clegg A. Cardioprotection against the toxic effects of anthracyclines given to children with cancer: A systematic review. Health Technol Assess 2007;11:1-84.

9. Sayed-Ahmed MM, Shouman SA, Rezk BM, Khalifa MH, Osman AM, El-Merzabani MM. Propionyl-L-carnitine as potential protective agent against adriamycin-induced impairment of fatty acid beta-oxidation in isolated heart mitochondria. Pharmacol Res 2000;41:143-50.

10. Alhomida AS, Duhaiman AS, al-Jafari AA, Junaid MA. Determination of L-carnitine, acylcarnitine and total carnitine levels in plasma and tissues of camel (Camelus dromedarius). Comp Biochem Physiol B Biochem Mol Biol 1995;111:441-5.
11. Pastoris O, Dossena $M$, Foppa $P$, Catapano $M$, Arbustini $E$, Bellini $O$, et al. Effect of $L$ carnitine on myocardial metabolism: Results of a balanced, placebo-controlled, double-blind study in patients undergoing open heart surgery. Pharmacol Res 1998;37:115-22.

12. Nemoto S, Yasuhara K, Nakamura K, Miyoshi $Y$, Sakai A. Plasma carnitine concentrations in patients undergoing open heart surgery. Ann Thorac Cardiovasc Surg 2004;10:19-22.

13. Tei C, Ling LH, Hodge DO, Bailey KR, Oh JK, Rodeheffer RJ, et al. New index of combined systolic and diastolic myocardial performance: A simple and reproducible measure of cardiac function-a study in normals and dilated cardiomyopathy. J Cardiol 1995;26:357-66.

14. Eto $G$, Ishii $M$, Tei $C$, Tsutsumi $T$, Akagi $T$, Kato $H$. Assessment of global left ventricular function in normal children and in children with dilated cardiomyopathy. J Am Soc Echocardiogr 1999;12:1058-64.

15. Singal PK, Deally CM, Weinberg LE. Subcellular effects of adriamycin in the heart: A concise review. J Mol Cell Cardiol 1987;19:817-28.

16. Von Hoff DD, Layard MW, Basa P, Davis HL Jr, Von Hoff AL, Rozencweig $\mathrm{M}$, et al. Risk factors for doxorubicin-induced congestive heart failure. Ann Intern Med 1979;91:710-7.

17. Okada Y, Horikawa K, Sano M. Echocardiographic evaluation of cardiotoxicity induced by anthracycline therapy. Gan To Kagaku Ryoho 1997;24:585-9.

18. Senju N, Ikeda S, Koga S, Miyahara $Y$, Tsukasaki K, Tomonaga $\mathrm{M}$, et al. The echocardiographic Tei-index reflects early myocardial damage induced by anthracyclines in patients with hematological malignancies. Heart Vessels 2007;22:393-7.

19. Yaris N, Akyuz C, Coskun T, Buyukpamukcu M. Serum carnitine levels of pediatric cancer patients. Pediatr Hemato Oncol 2002;19:1-8.

20. Yaris N, Ceviz N, Coskun T, Akytuz C, Buyukpamukcu M. Serum carnitine levels during the doxorubicin therapy. Its role in cardiotoxicity. J Exp Clin Cancer Res 2002;21:165-70.

21. Yoon HR, Hong YM, Boriack RL, Bennett MJ. Effect of L-carnitine supplementation on cardiac carnitine palmitoyltransferase activities and plasma carnitine concentrations in adriamycin-treated rats. Pediatr Res 2003;53:788-92.

22. Andrieu-Abadie N, Jaffrezou JP, Hatem S, Laurent G, Levade T, Mercadier JJ. L-carnitine prevents doxorubicin-induced apoptosis of cardiac myocytes: Role of inhibition of ceramide generation. FASEB J 1999;13:1501-10.

23. Goa KL, Brogden RN. L-Carnitine. A preliminary review of its pharmacokinetics, and its therapeutic use in ischaemic cardiac disease and primary and secondary carnitine deficiencies in relationship to its role in fatty acid metabolism. Drugs 1987;34:1-24.

24. Kawasaki N, Lee JD, Shimizu H, Ueda T. Long-term L-carnitine treatment prolongs the survival in rats with adriamycininduced heart failure. J Card Fail 1996;2:293-9.

How to cite this article: Khositseth A, Jirasakpisarn S, Pakakasama $\mathrm{S}$, Choubtuym L, Wattanasirichaigoon D. Carnitine levels and cardiac functions in children with solid malignancies receiving doxorubicin therapy. Indian J Med Paediatr Oncol 2011;32:38-42.

Source of Support: Mahidol University (2552-4),

Conflict of Interest: None declared. 